Research Article

\title{
Evaluation of Acid Leaching on the Removal of Heavy Metals and Soil Fertility in Contaminated Soil
}

\author{
Chen-Yao Chu and Tzu-Hsing Ko $(1)$ \\ Anxi College of Tea Science, Fujian Agriculture and Forestry University, Fuzhou 350002, China \\ Correspondence should be addressed to Tzu-Hsing Ko; hsingko@gmail.com
}

Received 12 March 2018; Accepted 8 May 2018; Published 4 June 2018

Academic Editor: Amit Bhatnagar

Copyright (C) 2018 Chen-Yao Chu and Tzu-Hsing Ko. This is an open access article distributed under the Creative Commons Attribution License, which permits unrestricted use, distribution, and reproduction in any medium, provided the original work is properly cited.

\begin{abstract}
Heavy metal-contaminated soils were leached with various acid reagents, and a series of treatments was assessed to understand soil fertility after acid leaching. Aqua regia digestion and a five-step sequential extraction procedure were applied to determine heavy metal distribution. The average total concentrations of $\mathrm{Zn}, \mathrm{Cd}, \mathrm{Cu}$, and $\mathrm{Pb}$ for contaminated soil were 1334, 25, 263, and $525 \mathrm{mg} \cdot \mathrm{kg}^{-1}$ based on the ICP/AES quantitative analysis. Other than $\mathrm{Pb}$ extracted by $\mathrm{H}_{2} \mathrm{SO}_{4}$, over $50 \%$ removal efficiency of other heavy metals was achieved. A five-step sequential extraction revealed that the bound-to-carbonate and bound-to-Fe-Mn oxides were the major forms of the heavy metals in the soil. The addition of organic manure considerably promoted soil fertility and increased soil $\mathrm{pH}$ after acid leaching. Seed germination experiments demonstrated that after acid leaching, the soil distinctly inhibited plant growth and the addition of manure enhanced seed germination rate from $35 \%$ to $84 \%$. Furthermore, the procedure of soil turnover after acid leaching and manure addition greatly increased seed germination rate by $61 \%$ and shortened the initial germination time. Seed germination in untreated soil was superior to that in acid-leached soil, illustrating that the phytotoxic effect of acid leaching is more serious than that of heavy metals.
\end{abstract}

\section{Introduction}

Soil pollution is a serious environmental issue worldwide $[1,2]$. Heavy metals are considered a serious soil pollutant because of their toxicity, persistence, and nondegradable characteristics in the environment [3-5]. In addition, the self-purification process of heavy metals present in contaminated soil is slower than that in contaminated air and water; thus, inadequate treatment of contaminated soil can pose a great human health risk. In Taiwan, more than 50,000 hectares of farmland has been contaminated by heavy metals to the fourth level classification, and more than 160 sites have been identified to be contaminated by heavy metals. Surveys state that approximately 785 hectares of farmland is contaminated by zinc to the fifth level classification [6].

The Er-Jen River located in the south western Taiwan is one of the most seriously contaminated rivers, caused by the waste from metal reclamation, smelting, and disposal of motors and electrical capacitors that released a large amount of heavy metals, polychlorinated biphenyls (PCBs), and polychlorinated dibenzo-p dioxins and dibenzofurans (PCDD/DFs) into the water [7]. Due to lack of environmental consciousness during early agricultural cultivation, the Er-Jen River was used as an irrigation source, which caused a detrimental heavy metal contamination to the paddy field. Therefore, remediation of the contaminated farmland near the Er-Jen River is of high priority.

To remediate heavy metal-contaminated soils, many effective techniques have been developed and employed, such as electrokinetics, phytoremediation, chemical extraction, vitrification, solidification, stabilization, and flotation [8-11]. However, soil washing is the most commonly used treatment technology for remediation of metalcontaminated soil. Several washing reagents, namely, water, acids, bases, chelating agents, alcohol, and other additives, have been investigated [12]. Increased attention has been recently focused on the use of citric acid or the chelating agents such as ethylenediaminetetraacetic acid 
(EDTA), nitrilotriacetic acid (NTA), and diethylenetriaminepentaacetic acid (DTPA) to remove heavy metals from contaminated soils [13-15].

Although acid leaching is an effective treatment for heavy metal removal from soil, it severely damages soil fertility and its use for remediating farmland is timeconsuming. The rapid enrichment of soil fertility after acid leaching is increasingly becoming a topic of concern for farmers. Therefore, this study used acid leaching techniques to remove heavy metals from contaminated farmland that can be helpful in understanding the mobility and bioavailability of metals in contaminated soil and to investigate the extraction efficiencies of heavy metals. In addition, the assessment of soil fertility and seed germination tests after the acid leaching procedure were investigated to understand the condition of remediation in the contaminated farmland.

\section{Experimental}

2.1. Sampling Area. Soil samples were collected from the top layer $(0-30 \mathrm{~cm})$ of a paddy field near the Er-Jen River in Tainan city, Taiwan province, China, which has been recognized as a previous history of irrigation with metals-rich wastewater. The paddy field contaminated with heavy metals has been strictly prohibited cultivating. Soil samples were collected by mixing ten subsamples from each site within a $50 \times 50$ meter area and were recorded for the central point position by using GPS equipment. The soil samples were air-dried at room temperature and then were ground with an agate mortar to pass through a $2 \mathrm{~mm}$ sieve. After sieving, the soil samples were experimentally pretreated by a vortex mixer with $100 \mathrm{rpm}$ for $24 \mathrm{~h}$ to ensure the complete mixing of the samples.

2.2. Chemical Analysis. Soil properties, including soil $\mathrm{pH}$, organic matters, soil texture, and cation exchange capacity, were determined. Particle size distribution was obtained by the pipette method after removal of carbonate, organic matters, and $\mathrm{MnO}_{2}$. Carbonate was removed by $1 \mathrm{M} \mathrm{NaOAc}$ with a pH 5 at $60^{\circ} \mathrm{C}$, and organic matters and $\mathrm{MnO}_{2}$ were digested by $30 \% \mathrm{H}_{2} \mathrm{O}_{2}$ [16]. The soil $\mathrm{pH}$ value was measured on a mixture of $1: 1$ soil/deionized water by a glass electrode [17]. Organic matter content was determined by the Walkley-Black wet oxidation method [18]. Cation exchange capacity was determined by the ammonium acetate method at $\mathrm{pH}=7$ [19]. Total content of heavy metals in soils was extracted by aqua regia digestion with a volume ratio of $1: 3$ $\mathrm{HNO}_{3} / \mathrm{HCl}$ at $120^{\circ} \mathrm{C}$ for $8 \mathrm{~h}$. The suspension was filtered through a $0.2 \mu \mathrm{m}$ filter paper after the digestion process and was placed into precleaned $100 \mathrm{ml}$ volumetric flasks with $0.5 \mathrm{M} \mathrm{HNO}_{3}$ for analysis. The contents of heavy metals were analyzed by inductively coupled plasma atomic absorption spectrometry (ICP/AES). To preclude unexpected contaminations in the analysis procedure, all equipment used were washed with a phosphate-free soap and cleaned with deionized $\mathrm{H}_{2} \mathrm{O}$. The detection limits for metals were as follows: $\quad \mathrm{Cd} \quad\left(0.05 \mathrm{mg} \cdot \mathrm{kg}^{-1}\right), \quad \mathrm{Zn} \quad\left(0.02 \mathrm{mg} \cdot \mathrm{kg}^{-1}\right), \quad \mathrm{Pb}$ $\left(0.06 \mathrm{mg} \cdot \mathrm{kg}^{-1}\right)$, and $\mathrm{Cu}\left(0.05 \mathrm{mg} \cdot \mathrm{kg}^{-1}\right)$. The percentages of recoveries for each metal were ranged from $96.7 \%$ for $\mathrm{Cd}$ to
103.2\% for Zn. The standard stock reagents (Merck, Germany) containing $1000 \mathrm{mg} \cdot \mathrm{kg}^{-1}$ of metals were used. Calibration reagents containing between 0.5 and $5000 \mathrm{mg} \cdot \mathrm{kg}^{-1}$ of $\mathrm{Cd}, \mathrm{Cu}$, $\mathrm{Pb}$, and $\mathrm{Zn}$ in $3 \% \mathrm{HNO}_{3}$ were daily prepared.

2.3. Acid Leaching Experiment. In this study, five acid reagents were taken into account for leaching heavy metals from contaminated soil, including $0.05 \mathrm{M} \mathrm{HNO}_{3}, \mathrm{HCl}$, $\mathrm{H}_{3} \mathrm{PO}_{4}$, and $\mathrm{H}_{2} \mathrm{SO}_{4}$. A liquid-to-soil ratio of $1: 10$ was adopted by adding $5 \mathrm{~g}$ of soil with $50 \mathrm{~mL}$ above acid reagents in a glass vessel, and they were continuously stirred at $100 \mathrm{rpm}$ for $5 \mathrm{~h}$. After leaching experiments, the suspension was centrifuged at $3500 \mathrm{rpm}$ for $30 \mathrm{~min}$ and then was filtered through a $0.2 \mu \mathrm{m}$ membrane filter for metals analysis. The contents of metals were analyzed by ICP/AES. To reduce the systematic errors, duplicate measurements were carried out for each sample, and the average values were determined. A five-step sequential extraction procedure used in this study was developed by Tessier [20]. The five fractions of bound heavy metals included the following: exchangeable form (EXC) was extracted with $1 \mathrm{M} \mathrm{NH}_{4} \mathrm{OAc}$ at $\mathrm{pH} 7$, carbonates form (CAR) was extracted with $1 \mathrm{M} \mathrm{NaOAc}$ at $\mathrm{pH} 5, \mathrm{Fe}-\mathrm{Mn}$ oxide form (MNO) was extracted with $0.04 \mathrm{M} \mathrm{NH}_{2} \mathrm{OH} \cdot \mathrm{HCl}$ in $25 \%$ HOAc, organic matter and metals associated with easily oxidizable solids or compounds $(\mathrm{OM})$ were extracted with $\mathrm{H}_{2} \mathrm{O}_{2}(30 \%)$ at $\mathrm{pH} 2$ and $0.02 \mathrm{M} \mathrm{HNO}_{3}$, and residual form (RES) was extracted with a 5:1 mixture of $\mathrm{HF}-\mathrm{HClO}_{4}$. All extracted reagents were centrifuged for $30 \mathrm{~min}$ at $10000 \mathrm{rpm}$ and filtered with a $0.2 \mu \mathrm{m}$ Teflon filter. The suspensions were analyzed by ICP/AES. Soil particle size is an important factor to affect removal efficiency of heavy metals. However, it is difficult to screen soil particle size when the in situ remediation is throughout used to a real heavy metal-contaminated site. Therefore, the effect of soil particle size is not mentioned in this study.

2.4. Seed Germination Experiment. For the germination tests, seeds of cabbage (Brassica chinensis L.) were used because this species is a general vegetable and can be popularly seen for a whole year. Twenty-five seeds of cabbage were sowed in a sterilized individual tray $\left(15 \times 20 \times 3 \mathrm{~cm}^{3}\right)$ containing $1200 \mathrm{~cm}$ [3] of modified leached soils. Duplicate of the seed germination experiment was simultaneously conducted. The trays were placed in a greenhouse at $25-28^{\circ} \mathrm{C}$ and $70 \% \mathrm{hu}-$ midity. The experiment was examined daily for 30 days, and seeds were recognized to have germinated when the cotyledon was observed. After cotyledon appearance, the root lengths in each tray were measured and recorded every $12 \mathrm{~h}$. The untreated soil sample was also conducted under the identical condition for comparison. To assess the seed germination criteria, the percentage of relative seed germination was chosen to understand the seed germination condition [21].

\section{Results and Discussion}

The physical and chemical properties of the soil samples along with their total heavy metal concentrations are listed 
TABLE 1: The brief description of contaminated soil used in this study.

\begin{tabular}{|c|c|}
\hline Property & Original soil \\
\hline Texture & Sandy clay loam \\
\hline $\mathrm{pH}$ & $7.6 \pm 0.11$ \\
\hline Organic matter (\%) & $1.91 \pm 0.18$ \\
\hline $\mathrm{CEC}\left(\mathrm{cmol} \cdot \mathrm{kg}^{-1}\right)$ & $4.58 \pm 0.21$ \\
\hline Total N (\%) & $0.13 \pm 0.01$ \\
\hline Total P (\%) & $2.82 \pm 0.10$ \\
\hline Total K (\%) & $1.74 \pm 0.04$ \\
\hline Available $\mathrm{N}\left(\mathrm{mg} \cdot \mathrm{kg}^{-1}\right)$ & $22.4 \pm 1.17$ \\
\hline Available P $\left(\mathrm{mg} \cdot \mathrm{kg}^{-1}\right)$ & $187 \pm 8.60$ \\
\hline Available $\mathrm{K}\left(\mathrm{mg} \cdot \mathrm{kg}^{-1}\right)$ & $764 \pm 40.54$ \\
\hline \multicolumn{2}{|c|}{$\begin{array}{l}\text { Total metal concentrations } \\
\text { (average content, } \mathrm{mg} \cdot \mathrm{kg}^{-1} \text { ) }\end{array}$} \\
\hline $\mathrm{Zn}$ & $1334 \pm 83$ \\
\hline $\mathrm{Cd}$ & $25 \pm 3$ \\
\hline $\mathrm{Cu}$ & $263 \pm 18$ \\
\hline $\mathrm{Pb}$ & $525 \pm 31$ \\
\hline
\end{tabular}

in Table 1. The average total concentrations of $\mathrm{Zn}, \mathrm{Cd}, \mathrm{Cu}$, and $\mathrm{Pb}$ were $1334,25,263$, and $525 \mathrm{mg} \cdot \mathrm{kg}^{-1}$, respectively, and their maximum concentrations of $\mathrm{Zn}, \mathrm{Cd}, \mathrm{Cu}$, and $\mathrm{Pb}$ were $4852,46,1470$, and $1430 \mathrm{mg} \cdot \mathrm{kg}^{-1}$, respectively. The total heavy metal concentrations were not only higher than the tolerable limits recommended by the World Health Organization (WHO) and European Union (EU), but also exceeded the Chinese standard for agricultural soil [22]. This contaminated site needs to be appropriately treated to avoid heavy metals moving into deeper layers and causing phreatic zone pollution. As shown in Table 1, the organic matter content is much lower than the normal content. This is because that the Er-Jen River is contaminated by metal reclamation, smelting, and electrical capacitors and results in a high content of heavy metal accompanying a low $\mathrm{pH}$ value. Due to long-term irrigation from Er-Jen River, it is believed that the organic content of soil in this site is much lower than that of the uncontaminated site. The removal efficiency of heavy metals by various acid reagents is shown in Figure 1. The leaching experiments indicated that $\mathrm{Zn}$ and $\mathrm{Cu}$ had the highest removal efficiency and more than $70 \%$ removal efficiency was achieved for all acid reagents. For the $\mathrm{Cd}$ species, regardless of the acid reagents used, the removal efficiency ranged from $55 \%$ to $66 \%$, indicating a high chemical affinity between the $\mathrm{Cd}$ and the soil, yielding lower removal efficiency for all acid reagents. A sequential extraction method was used to determine the Cd distribution in the surface sediment and found the major binding structure between $\mathrm{Cd}$ and soil was attributed to a residual form [23]. Among the four acid reagents, $\mathrm{HNO}_{3}$ had the lowest $\mathrm{Cd}, \mathrm{Zn}$, and $\mathrm{Cu}$ removal efficiency, whereas $\mathrm{H}_{2} \mathrm{SO}_{4}$ had the highest $\mathrm{Cd}, \mathrm{Zn}$, and $\mathrm{Cu}$ removal efficiency; this result was not observed for $\mathrm{Pb}$. To further understand the speciation distribution of heavy metal in soil, the chemical sequential extraction was used and is shown in Figure 2. The highest $\mathrm{Cd}$ concentration was associated with the RES fraction, whereas the EXC had the lowest concentration. The presence of $\mathrm{Cd}$ in the RES fraction was consistent with the result obtained by Mendoza et al. in which their report

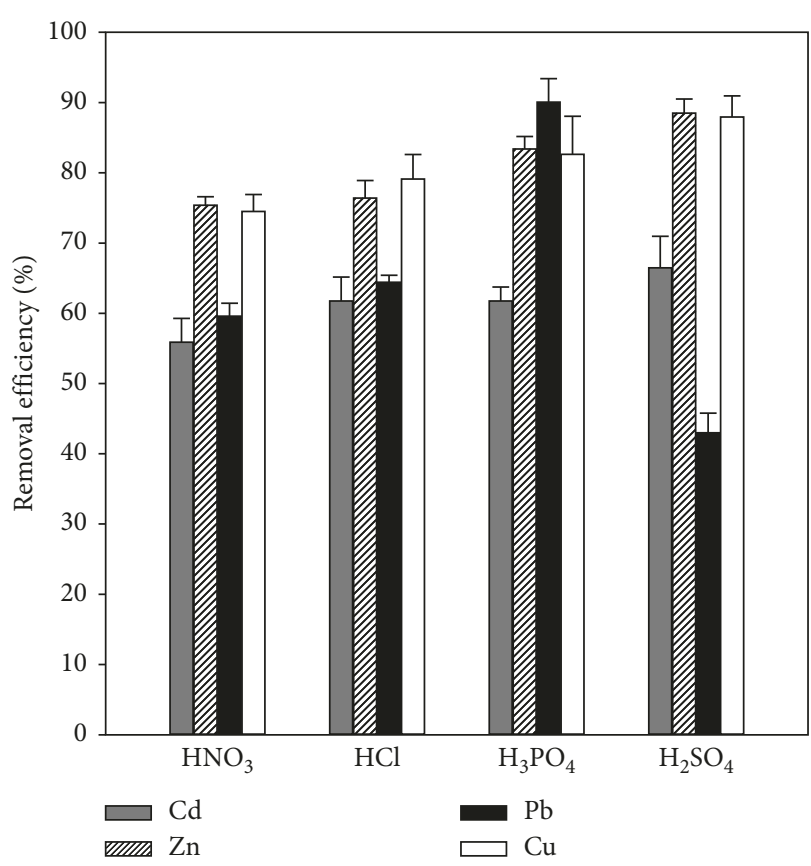

Figure 1: Removal efficiency of heavy metals by using various acid reagents.

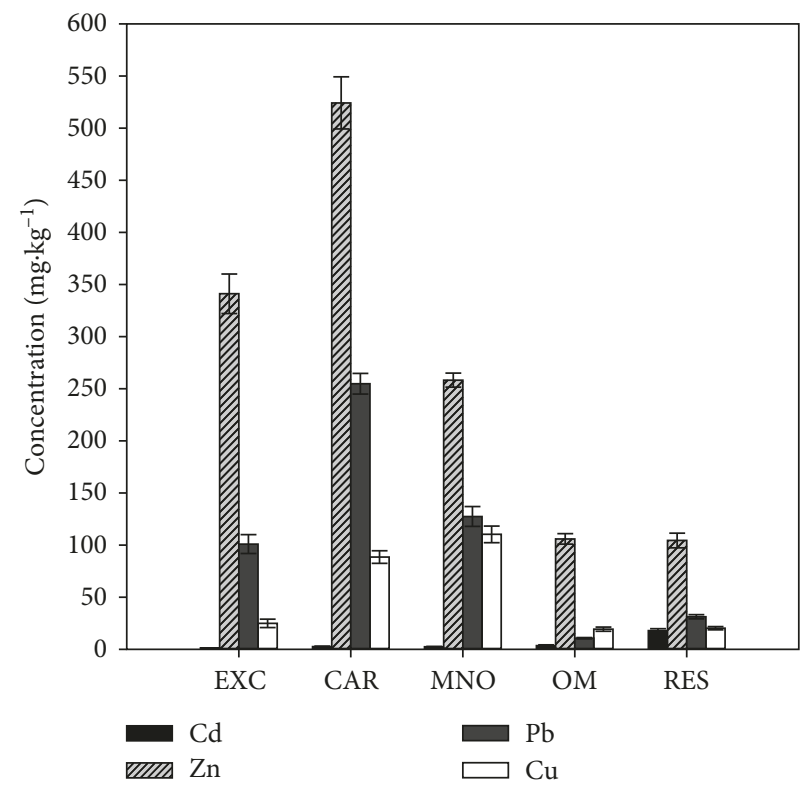

FIgURE 2: The sequential fractionations of heavy metals in contaminated soil.

showed that Cd was distributed predominantly in the residual form with a value of $45 \%$ in the contaminated soil [24]. Thus, the Cd retained in the crystal lattices of minerals has a strong bond and consequently is not easily released into the environment. The overall percentage of $\mathrm{Cd}$ in the fractions was in the order: RES $>$ OM $>$ CAR $>$ MNO $>$ EXC. Unlike Cd, the largest portion of Zn was observed in the CAR fraction $(39 \%)$ and followed in the descending order of $\mathrm{EXC}>\mathrm{MNO}>\mathrm{OM}>\mathrm{RES}$. This fraction could be easily 


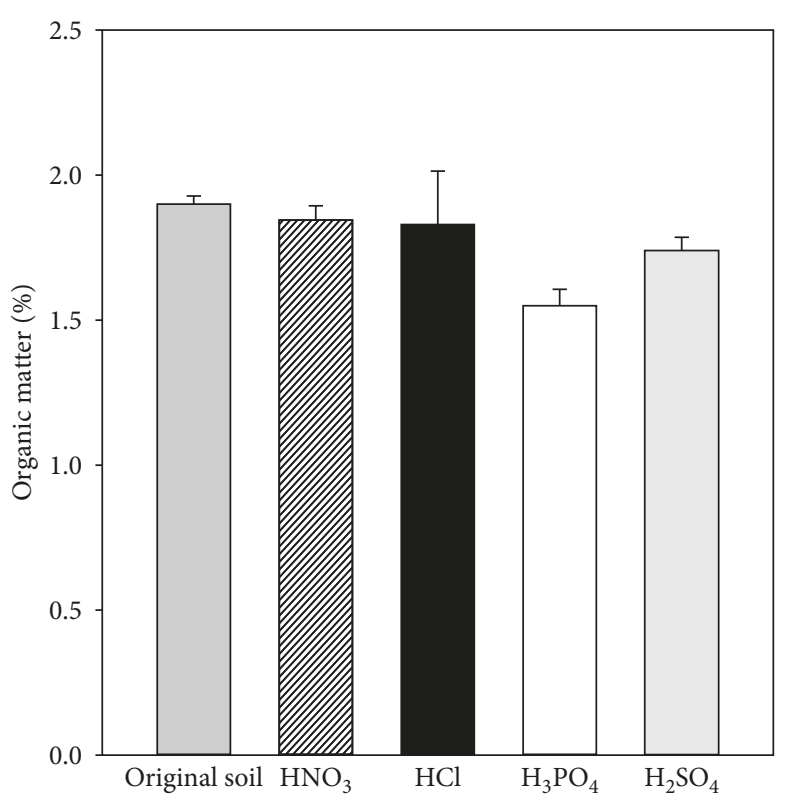

(a)

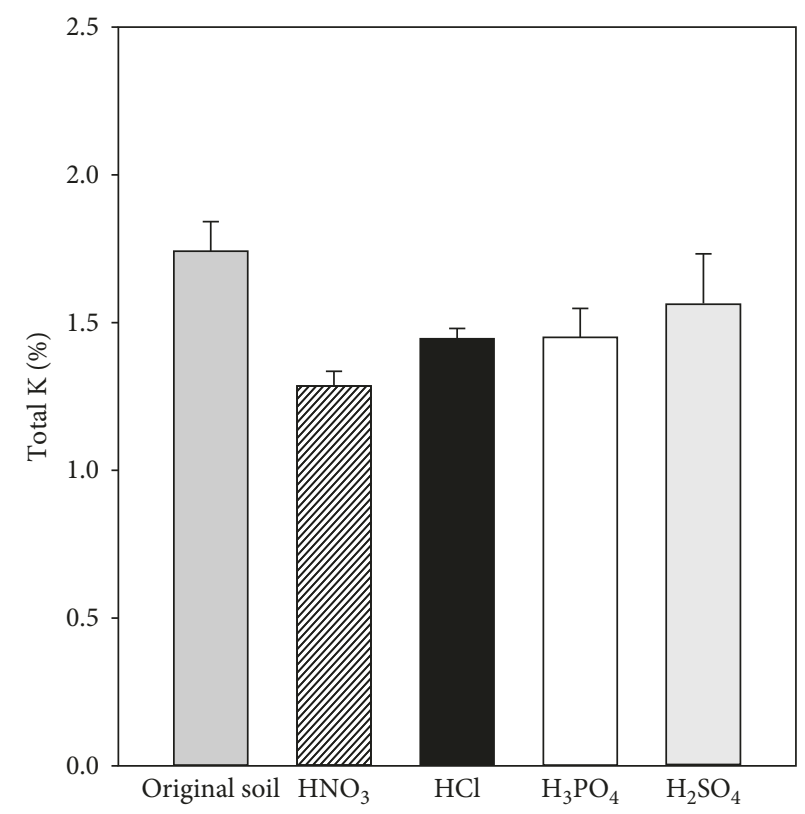

(c)

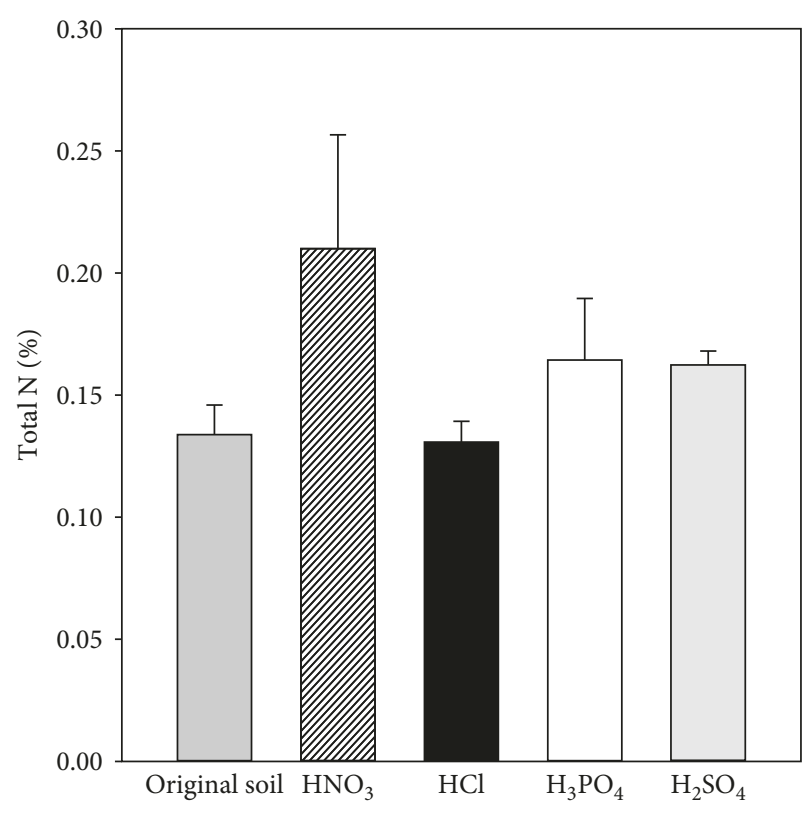

(b)

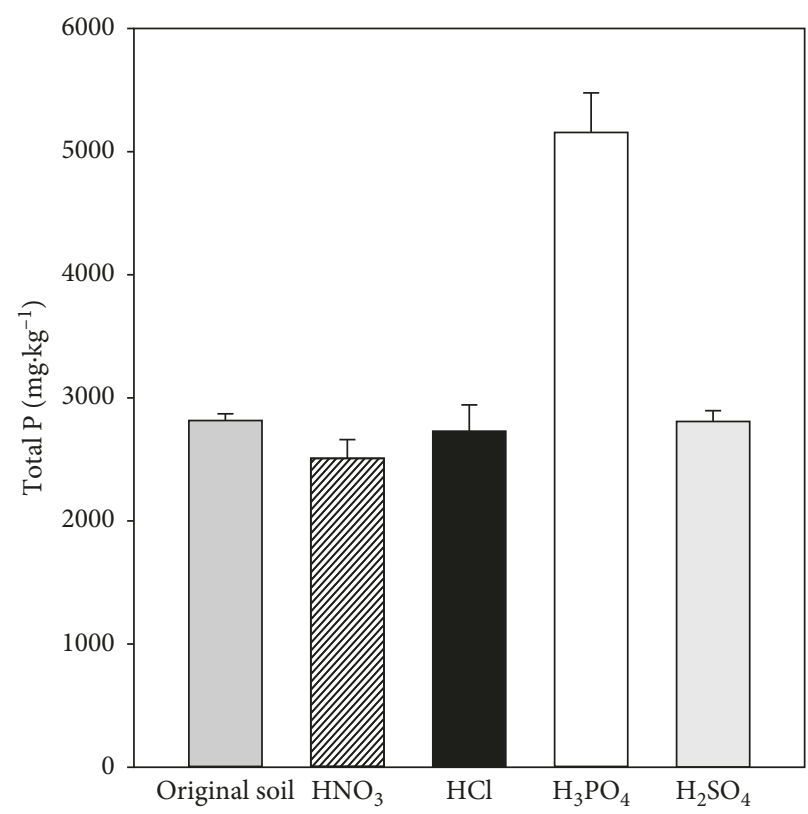

(d)

Figure 3: The changes in content of (a) organic matter, (b) total N, (c) total K, and (d) total P after leaching by various acid reagents.

made exchangeable under conditions such as $\mathrm{pH}$ change [25]. $\mathrm{Pb}$ and $\mathrm{Cu}$ demonstrated an identical trend in that CAR and $\mathrm{MNO}$ appeared to be the major fraction. The proportion of heavy metals bounds to Fe-Mn oxides was highly variable and depended on the depth of the water and redox reactions with the soils. The redox cycle is important in controlling Fe and $\mathrm{Mn}$ in most aquatic and soil systems. However, it varies seasonally in summer, when the oxygen between the water and soil interface often decreases. This causes the reduction of $\mathrm{Fe}^{3+}$ and $\mathrm{Mn}^{4+}$ into soluble $\mathrm{Fe}^{2+}$ and $\mathrm{Mn}^{2+}$, which is transported upward in the water column and oxygenated, resulting in the reoxidation of insoluble metals to settle the soil and repeat the cycle [26]. These forms of metals are potentially dangerous for plants because they can transform into being bioavailable under environmental changes [27]. Organic matter $(\mathrm{OM})$, nitrogen $(\mathrm{N})$, potassium $(\mathrm{K})$, and phosphor (P) are important substances for vegetable and plant growth in soil. To understand the changes in these substances after acid reagents leaching, OM, total N, total K, and total $\mathrm{P}$ contents were determined and are depicted in Figure 3. The content of OM in the soil decreases by $18.5 \%$ and $8.74 \%$ when $\mathrm{H}_{3} \mathrm{PO}_{4}$ and $\mathrm{H}_{2} \mathrm{SO}_{4}$ were used for pickling, respectively. No significant change in the $\mathrm{OM}$ content for $\mathrm{HNO}_{3}$ and $\mathrm{HCl}$ was observed. The total $\mathrm{N}$ content increased 


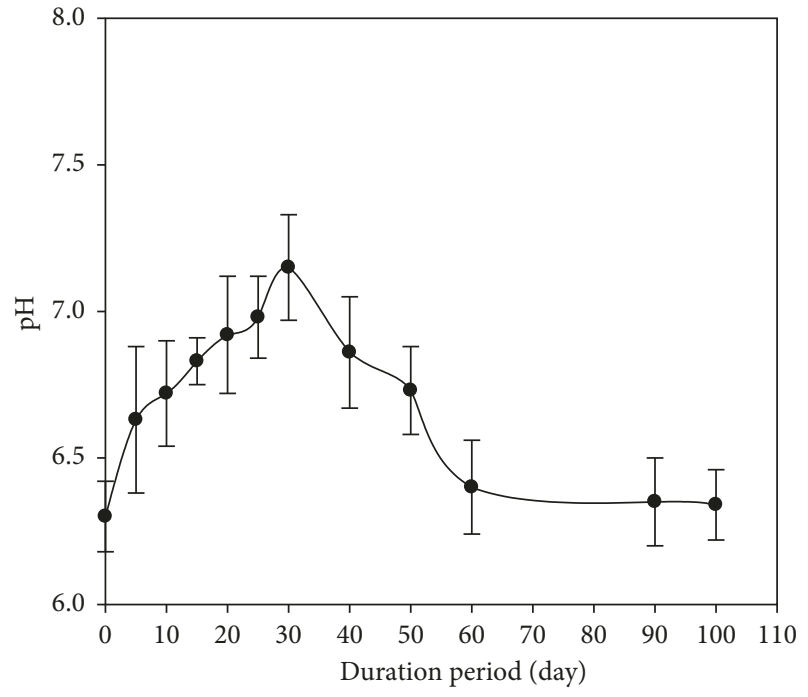

FIGURE 4: The change in soil $\mathrm{pH}$ as a function of the duration period after $\mathrm{HCl}$ leaching and fertilized by adding organic manure.

by $57.07 \%, 22.86 \%$, and $21.47 \%$ after leaching with $\mathrm{HNO}_{3}$, $\mathrm{H}_{3} \mathrm{PO}_{4}$, and $\mathrm{H}_{2} \mathrm{SO}_{4}$, respectively. The $\mathrm{N}$ content decreased by $10.65 \%$ after leaching with $\mathrm{HCl}$. Higher $\mathrm{N}$ content after $\mathrm{HNO}_{3}$ treatment may be attributed to the presence of $\mathrm{NO}_{3}{ }^{-}$ released from $\mathrm{HNO}_{3}$ during the leaching process. Figure 3(d) shows the phosphorus content in the soil after acid leaching. All reagents, except $\mathrm{H}_{3} \mathrm{PO}_{4}$, reduced the total $\mathrm{P}$ content after acid leaching. No significant difference was noted between the original soil and the other three acid reagents. The $\mathrm{P}$ content increased by $83.17 \%$ after leaching by $\mathrm{H}_{3} \mathrm{PO}_{4}$, presumably because of the presence of $\mathrm{PO}_{4}{ }^{3-}$ released from the $\mathrm{H}_{3} \mathrm{PO}_{4}$ during leaching process. The result of changes in total $\mathrm{K}$ is also depicted in Figure 3(c). The soil $\mathrm{K}$ concentration changed because of acid liquid precipitation. $\mathrm{HNO}_{3}$ reduced the total $\mathrm{K}$ content by $26.2 \%$, followed by others in a descending order $\mathrm{HCl}>\mathrm{H}_{3} \mathrm{PO}_{4}>\mathrm{H}_{2} \mathrm{SO}_{4}$. Commercial organic manure was used after the leaching treatment to fertilize the soil. Commercial organic manure contains $21 \%$ $\mathrm{OM}, 4.2 \%$ total $\mathrm{N}, 4.1 \%$ total $\mathrm{P}$, and $3.5 \%$ total $\mathrm{K}$. Most manure containing considerable amounts of soluble salts increases soil's electrical conductivity (EC), resulting in damage to plants. The result of the experiments showed that the EC increased after manure treatment and reached stability after 30 days. Over 30 days, the EC ranged from 0.86 to $0.41 \mathrm{mS} \cdot \mathrm{cm}^{-1}$, an acceptable range for plant growth. Figure 4 shows the changes in soil $\mathrm{pH}$ as a function of duration after $\mathrm{HCl}$ leaching and fertilization by organic manure. The initial $\mathrm{pH}$ for original and leached soils was 7.6 and 6.3, respectively. The acid leaching treatment reduced the soil $\mathrm{pH}$ consequentially caused an unfavorable effect to crops cultivation. The $\mathrm{pH}$ increased with the duration and reached a maximum of 7.02 at 30 days; it then gradually decreased and eventually stabilized to approximately 6.3. The addition of organic manure significantly improved soil $\mathrm{pH}$ over a short period; however, in the long-term, the soil $\mathrm{pH}$ returned to a meta-acid state, which was probably associated with the soil buffering power. Figure 5 shows the changes in the OM, total N, total $\mathrm{P}$, and total $\mathrm{K}$ contents as a function of the duration after $\mathrm{HCl}$ leaching and fertilization treatment. The identical feature could be observed after the addition of organic manure, which increased the $\mathrm{OM}$, total $\mathrm{N}$, total $\mathrm{P}$, and total $\mathrm{K}$ content within 30 days. Over the first 15 days, the $\mathrm{OM}$ and total $\mathrm{N}$ contents became more than twice of this manure addition, and a steady state was gradually achieved. However, the total $\mathrm{K}$ content rapidly increased with the duration with the highest content value of $2.5 \%$ within 5 days. On the basis of these findings, the organic manure additive improves soil fertility within a short period. To assess the suitability of farmland for cultivation, a seed germination experiment was performed to evaluate suitability for planting after various treatments. Seeds were cultivated in an incubator and observed daily for germination with the seed germination rate as a function of time at various treatments presented in Figure 6. The lowest germination rate was observed when soil was treated through acid leaching because after acid leaching the soil fertility decreased and affected plant growth. On the other hand, initial seed germination occurred earlier than the other treatments. Although heavy metals were moderately removed after acid leaching, the nutrient loss was a major barrier to seed germination. After the addition of organic manure, the seed germination rate considerably increased by more than $80 \%$ and the initial seed germination time was four days, earlier than that of the experiments assessed after acid leaching. Notably, the seed germination rate in untreated soil was superior to that in acid-leached soil. This demonstrates that the inhibition effect of acid leaching to the plant is more serious than that of heavy metals, and the addition of organic manure could be a suitable approach to improve soil fertility and plant cultivation. To obtain a higher seed germination rate, the procedure of soil turnover was applied simultaneously. As shown in Figure 6, the procedure of adding manure to soil turnover rapidly increased the seed germination rate and initial seed germination time, and a seed germination rate of approximately $85 \%$ was achieved. The procedure of soil turnover diluted heavy metals and acidic species and thus resulted in the redistribution of these species.

Although seed germination rate is a suitable indicator to evaluate soil fertility, heavy metal concentration in test plants should be considered to ensure food safety. Therefore, cabbage roots and leaves were collected and analyzed to understand heavy metal distribution. The experimental result is presented in Table 2. The major uptake was found in the root of cabbage, and the fraction of $\mathrm{Cd}, \mathrm{Zn}, \mathrm{Pb}$, and $\mathrm{Cu}$ uptake by the root was $46.8 \%, 51.3 \%, 17 \%$, and $25.4 \%$, respectively. This finding is in agreement with the observation of Shi et al., who reported that heavy metal concentration is much higher in the root than in the shoot and leaf [28]. The root is the first mode of entry for heavy metal pollutants from the soil into the plant. Nevertheless, it excretes organic acids, amino acids, sugars, and growth substances into the rhizosphere, affecting metal adsorption. By changing the physiochemical properties of the rhizosphere, the heavy metals will be detained in the roots through chelation, complexation, and disposition with root exudates. Notably, 


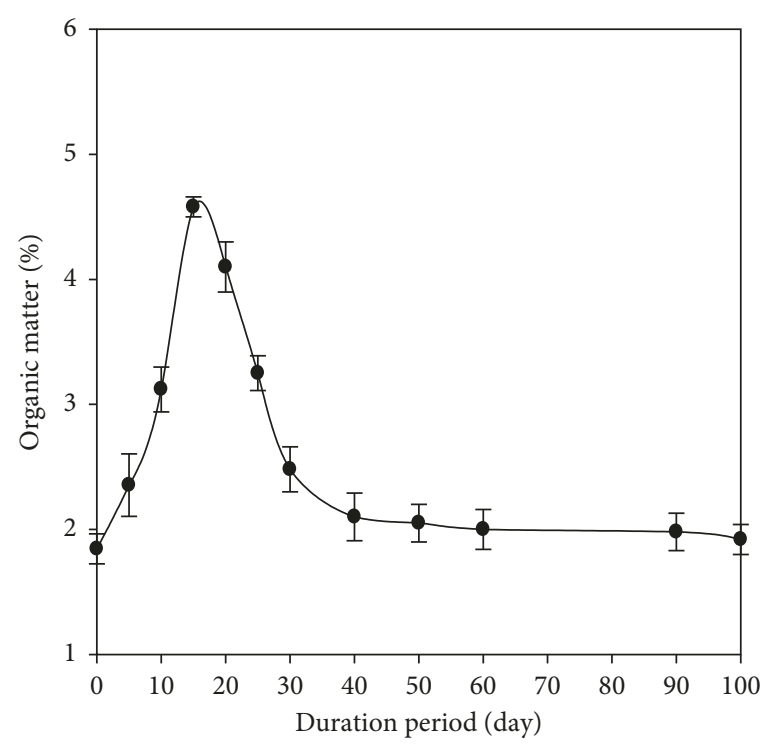

(a)

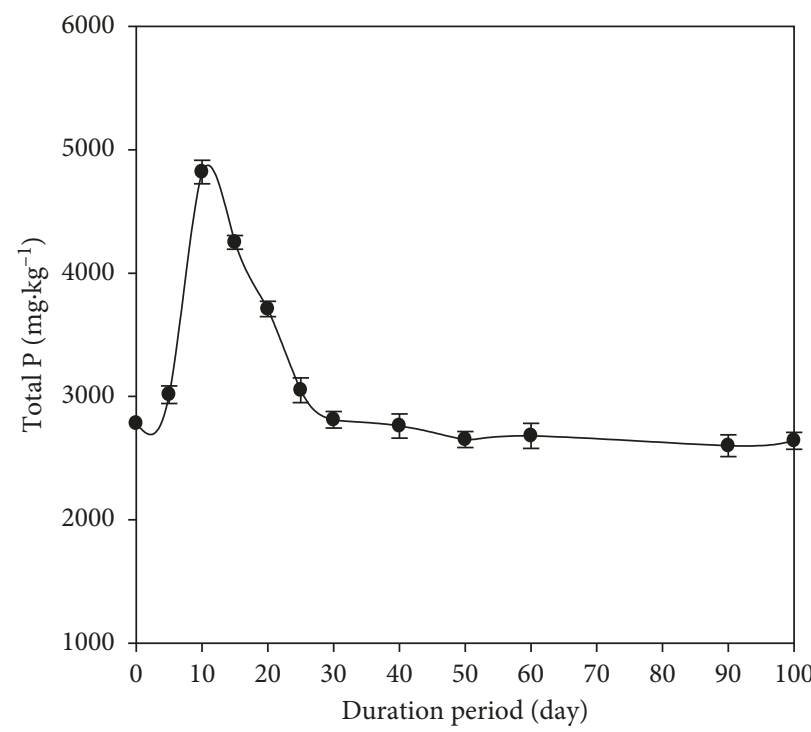

(c)

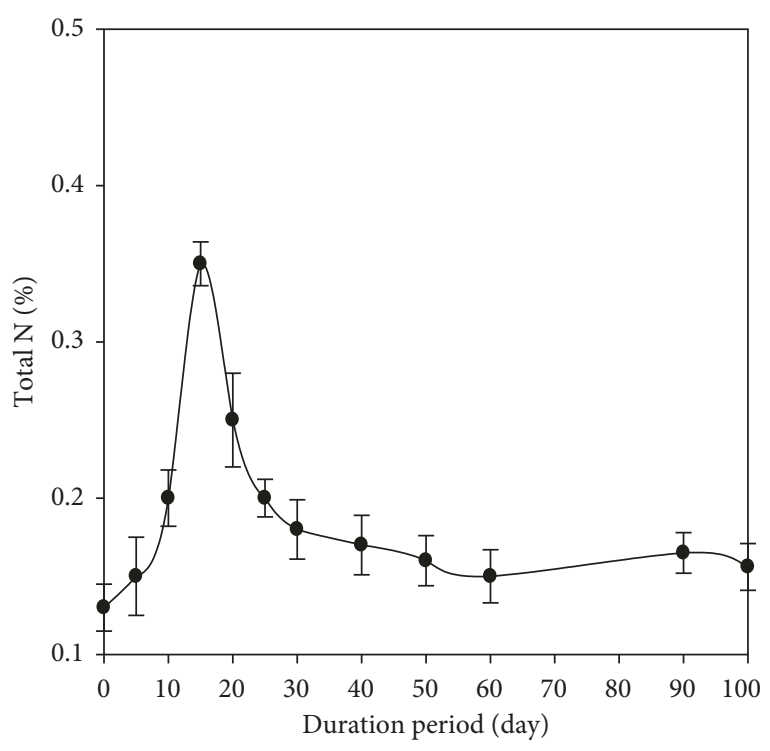

(b)

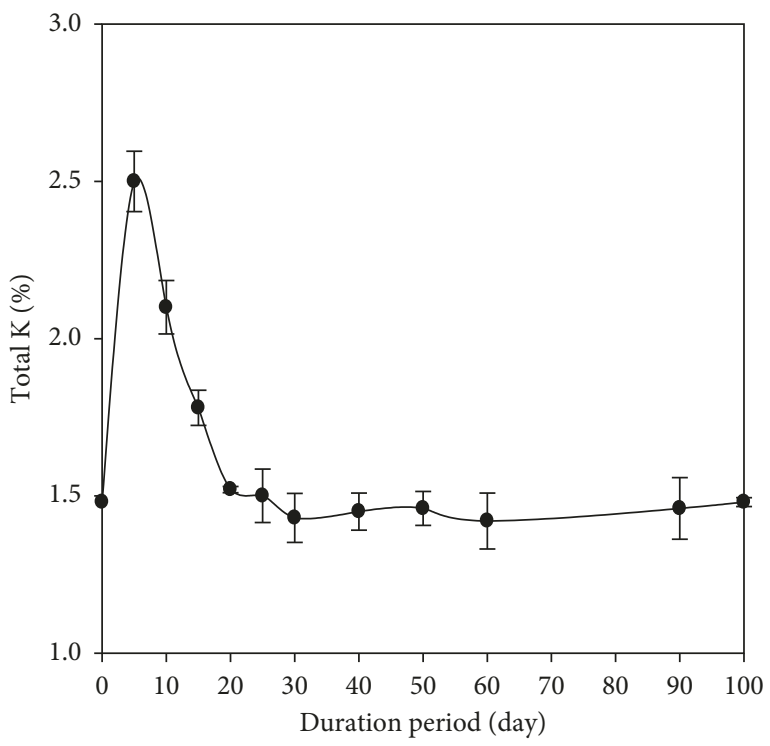

(d)

Figure 5: The changes in contents of (a) organic matter, (b) total N, (c) total P, and (d) total K as a function of the duration period after $\mathrm{HCl}$ leaching and fertilized by organic manure.

in this case, the $\mathrm{Pb}$ uptake by the root was the lowest, whereas a much higher fraction was noted for $\mathrm{Zn}$; the leaf demonstrated the same result. $\mathrm{Pb}$ and $\mathrm{Zn}$ are essential elements for plants growth, but their excessive amounts in soil lead to the inhibition and poisoning of plants. The normal $\mathrm{Pb}$, $\mathrm{Cu}$, and $\mathrm{Zn}$ contents in plants are $0.5-10 \mathrm{mg} \cdot \mathrm{kg}^{-1}$, $3-30 \mathrm{mg} \cdot \mathrm{kg}^{-1}$, and $10-150 \mathrm{mg} \cdot \mathrm{kg}^{-1}$, respectively, whereas their toxic concentrations to plants are $100-400 \mathrm{mg} \cdot \mathrm{kg}^{-1}$, 70-400 $\mathrm{mg} \cdot \mathrm{kg}^{-1}$, and 60-125 mg. $\mathrm{kg}^{-1}$, respectively [29]. Here, the $\mathrm{Pb}, \mathrm{Zn}$, and $\mathrm{Cu}$ concentrations in bulk cabbage were $120.23 \mathrm{mg} \cdot \mathrm{kg}^{-1}, \quad 283.52 \mathrm{mg} \cdot \mathrm{kg}^{-1}$, and $37.14 \mathrm{mg} \cdot \mathrm{kg}^{-1}$, respectively. Except $\mathrm{Cu}, \mathrm{Pb}$ and $\mathrm{Zn}$ concentrations were slightly higher than the aforementioned range, indicating the soils after acid leaching and organic manure addition remain a risk when used to cultivate plants. The procedure of soil turnover may be a suitable approach to overcome this obstacle.

\section{Conclusions}

A series of acid leaching tests and soil fertility assessment for contaminated soil containing $\mathrm{Cd}, \mathrm{Pb}, \mathrm{Zn}$, and $\mathrm{Cu}$ were performed to investigate leaching behavior. Most heavy metals could be removed through acid leaching with a nearly $60 \%$ removal efficiency achieved. The major species for $\mathrm{Cd}$, $\mathrm{Zn}$, and $\mathrm{Cu}$ were distributed in residual, bound-tocarbonate, and bound-to-Fe-Mn oxides forms, respectively. The addition of organic manure distinctly increased soil nutrient content as well as soil $\mathrm{pH}$ within a short period. Seed 


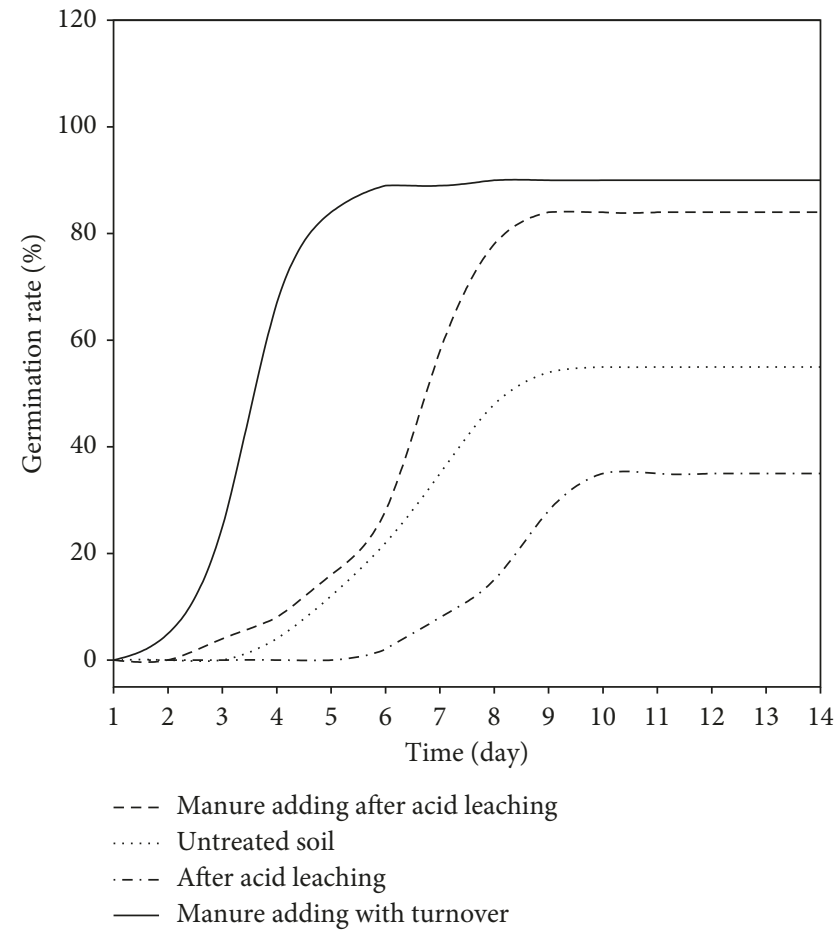

FIGURE 6: Seed germination rate as a function of time at various treatments.

TABLE 2: Distribution of heavy metal concentration at the root and leaf of cabbage.

\begin{tabular}{lcccc}
\hline & $\mathrm{Cd}\left(\mathrm{mg} \cdot \mathrm{kg}^{-1}\right)$ & $\mathrm{Zn}\left(\mathrm{mg} \cdot \mathrm{kg}^{-1}\right)$ & $\mathrm{Pb}\left(\mathrm{mg} \cdot \mathrm{kg}^{-1}\right)$ & $\mathrm{Cu}\left(\mathrm{mg} \cdot \mathrm{kg}^{-1}\right)$ \\
\hline Root & $1.47 \pm 0.04$ & $145.52 \pm 9.84$ & $20.45 \pm 1.74$ & $9.42 \pm 0.87$ \\
Leaf & $0.13 \pm 0.03$ & $65.85 \pm 2.42$ & $4.33 \pm 0.13$ & $3.84 \pm 0.27$ \\
Bulk & $3.14 \pm 0.21$ & $283.52 \pm 12$ & $120.23 \pm 8.87$ & $37.14 \pm 3.14$ \\
\hline
\end{tabular}

germination in untreated soil was superior to that in acidleached soil, revealing that the phytotoxic effect of acid leaching is more serious than that of heavy metals.

\section{Data Availability}

The data used to support the findings of this study are available from the corresponding author upon request.

\section{Conflicts of Interest}

The authors declare that there are no conflicts of interest regarding the publication of this paper.

\section{Acknowledgments}

This work was partially funded by Anxi College of Tea Science, Fujian Agriculture and Forestry University, and Yung-Hsing Financial Workshop Cooperation Company.

\section{References}

[1] A. Jamshidi-Zanjani and A. Khodadadi Darban, "A review on enhancement techniques of electrokinetic soil remediation," Pollution, vol. 3, no. 1, pp. 157-166, 2017.
[2] B. Yassir, E. F Sana, and P. Alain, "Contamination by trace elements of agricultural soils around Sidi Bou Othmane in abandoned mine tailings in Marrakech, Morocco," Pollution, vol. 2, no. 1, pp. 93-101, 2016.

[3] M. Klavinš, A. Briede, V. Rodinov, I. Kokorite, E. Pareleb, and I. Klavina, "Heavy metals in rivers of Latvia," Science of The Total Environment, vol. 262, no. 1-2, pp. 175-183, 2000.

[4] N. F. Y. Tam and Y. S. Wong, "Spatial variation of heavy metals in surface sediments of Hong Kong mangrove swamps," Environmental Pollution, vol. 110, no. 2, pp. 195205, 2000.

[5] C. G. Yuan, J. B. Shi, B. He, J. F. Liu, L. N. Liang, and G. B. Jing, "Speciation of heavy metals in marine sediments from the East China Sea by ICP-MS with sequential extraction," Environment International, vol. 28, no. 6, pp. 769-783, 2004.

[6] J. G. Sah and J. Y. Chen, "Study of the electrokinetic process on $\mathrm{Cd}$ and $\mathrm{Pb}$ spiked soils," Journal of Hazardous Materials, vol. 58, no. 1-3, pp. 301-315, 1998.

[7] Y. C. Ling, D. K. Soong, and M. K. Lee, "PCDD/DFS and coplanar pcbs in sediment and fish samples from the Er-Jen river in Taiwan," Chemosphere, vol. 31, no. 3, pp. 2863-2872, 1995.

[8] Q. Huang, Z. Yu, Y. Pang, Y. Wang, and Z. Cai, "Coupling bioleaching and electrokinetics to remediate heavy metal contaminated soils," Bulletin of Environmental Contamination and Toxicology, vol. 94, no. 4, pp. 519-524, 2015.

[9] W. Fu, K. Huang, H. H. Cai et al., "Exploring the potential of naturalized plants for phytoremediation of heavy metal contamination," International Journal of Environmental Research, vol. 11, no. 4, pp. 515-521, 2017.

[10] H. Park, K. Jung, R. D. Alorro, and K. Yoo, "Leaching behavior of Copper, Zinc and Lead from contaminated soil with citric acid," Materials Transactions, vol. 54, no. 7, pp. 12201223, 2013.

[11] C. S. Lee and M. M. Kao, "Effects of extracting reagents and metal speciation on the removal of heavy metal contaminated soils by chemical extraction," Journal of Environmental Science and Health, vol. 39, no. 5, pp. 1233-1249, 2004.

[12] R. A. Griffiths, "Soil-washing technology and practice," Journal of Hazardous Materials, vol. 40, no. 2, pp. 175-189, 1995.

[13] A. V. Singh and R. Singh, "Synthesis, characterization, and application of tamarind nitrilotriacetic acid resin in removal of heavy metal ions from industrial effluent," Environmental Progress and Sustainable Energy, vol. 32, no. 1, pp. 103-108, 2013.

[14] I. Tahmasbian, A. A. S. Sinegani, T. T. N. Nguyen, R. Che, T. D. Phan, and S. H. Bai, "Application of manures to mitigate the harmful effects of electrokinetic remediation of heavy metals on soil microbial properties in polluted soils," Environmental Science and Pollution Research, vol. 24, no. 34, pp. 26485-26496, 2017.

[15] A. Azis, H. Matsuyama, and M. Teramoto, "Dissociation rates of various heavy rare earth metal-diethylenetriaminepentaacetic acid complexes," Journal of Chemical Engineering of Japan, vol. 28, no. 3, pp. 334-339, 2005.

[16] G. E. Gee and J. W. Bauder, "Particle-size analysis," in Methods of Soil Analysis. Part I, A. Klute, Ed., p. 383, American Society of Agronomy, Madson, WI, USA, 2nd edition, 1986.

[17] E. O. McLean, "Soil pH and lime requirement," in Methods of Soil Analysis. Part II, A. L. Page, R. H. Miller, and D. R. Keeney, Eds., p. 199, American Society of Agronomy, Madson, WI, USA, 2nd edition, 1982. 
[18] D. W. Nelson and L. E. Sommer, "Total carbon, organic carbon, and organic matter," in Methods of Soil Analysis. Part II, A. L. Page, R. H. Miller, and D. R. Keeney, Eds., pp. 539-577, American Society of Agronomy, Madson, WI, USA, 2nd edition, 1982.

[19] J. D. Rhoades, "Cation exchange capacity," in Methods of Soil Analysis. Part II, A. L. Page, R. H. Miller, and D. R. Keeney, Eds., pp. 149-157, American Society of Agronomy, Madson, WI, USA, 2nd edition, 1982.

[20] A. Tessier, P. G. C. Campbell, and M. Bisson, "Sequential extraction procedure for the speciation of particulate trace metals," Analytical Chemistry, vol. 51, no. 7, pp. 844-851, 1979.

[21] N. J. Hoekstra, T. Bosker, and E. A. Lantinga, "Effects of cattle dung from farms with different feeding strategies on germination and initial root growth of cress (Lepidium sativum L.)," Agriculture, Ecosystems and Environment, vol. 93, no. 1-3, pp. 189-196, 2002.

[22] C. S. Lee and M. M. Kao, "Distribution of forms of heavy metals in soils contaminated by metallurgical smelter emissions," Journal of Environmental Science and Health Part A, vol. 39, no. 3, pp. 577-585, 2004.

[23] A. Naji, A. Ismail, and A. R. Ismail, "Chemical speciation and contamination assessment of $\mathrm{Zn}$ and $\mathrm{Cd}$ by sequential extraction in surface sediment of Klang River, Malaysia," Microchemical Journal, vol. 95, no. 2, pp. 285-292, 2010.

[24] C. J. Mendoza, R. T. Garrido, R. C. Quilodrán, C. M. Segovia, and A. J. Parada, "Evaluation of the bioaccessible gastric and intestinal fractions of heavy metals in contaminated soils by means of a simple bioaccessibility extraction test," Chemosphere, vol. 176, pp. 81-88, 2017.

[25] M. Lei, B. H. Liao, Q. R. Zeng, P. F. Qin, and S. Khan, "Fraction distributions of Lead, Cadmium, Copper, and Zinc in metal-contaminated soil before and after extraction with disodium ethylenediaminetetraacetic acid," Communications in Soil Science and Plant Analysis, vol. 39, no. 13-14, pp. 1963-1978, 2008.

[26] J. W. Moore, Inorganic Contaminants of Surface Water: Research and Monitoring Priorities, Springer-Verlag, Berlin, Germany, 1991.

[27] D. Papadopoulos, C. Pantazi, C. Savvides, K. J. Harlambous, A. Papadopoulos, and M. Loizidou, "A study on heavy metal pollution in marine sediments and their removal from dredged material," Journal of Environmental Science and Health Part A, vol. 32, no. 2, pp. 347-360, 1997.

[28] X. Shi, Y. Chen, S. Wang, X. Zhang, and Y. Yuan, "Growth and metal uptake of three woody species in lead/zinc and copper mine tailing," Acta Ecolog Sinica, vol. 31, pp. 18181826, 2011, in Chinese.

[29] D. B. Levy, E. F. Redente, and G. D. Uphoff, "Evaluating the phytotoxicity of $\mathrm{Pb}-\mathrm{Zn}$ tailings to big bluestem (Andropogon gerardii vitman) and switchgrass (Panicum virgatum L.)," Soil Science, vol. 164, no. 6, pp. 363-375, 1999. 

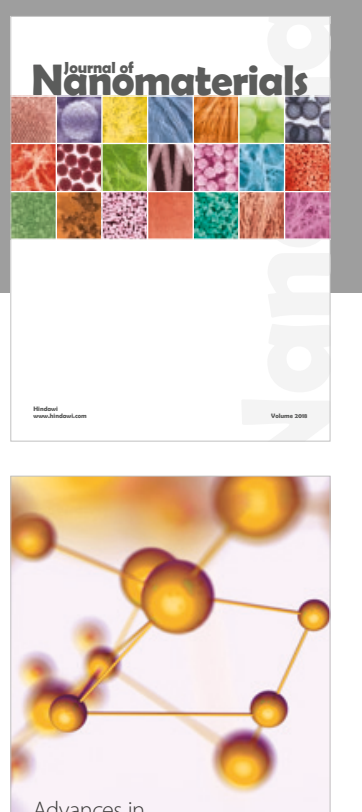

Physical Chemistry
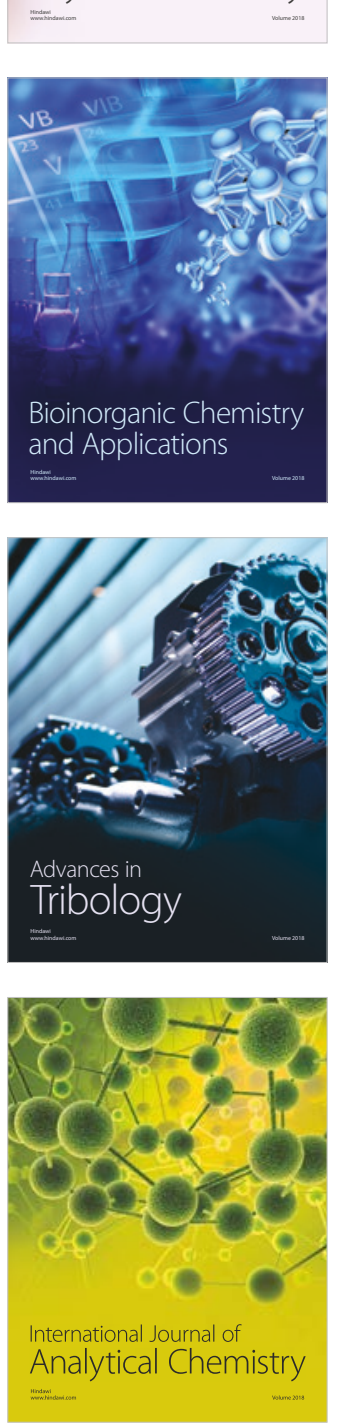

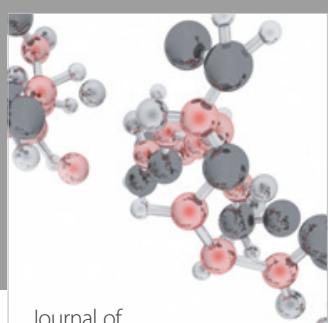

Analytical Methods

in Chemistry

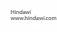

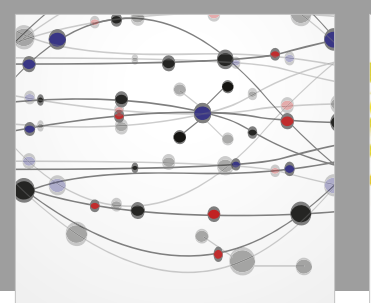

The Scientific World Journal

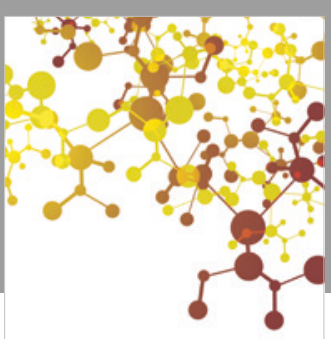

Journal of

Applied Chemistry
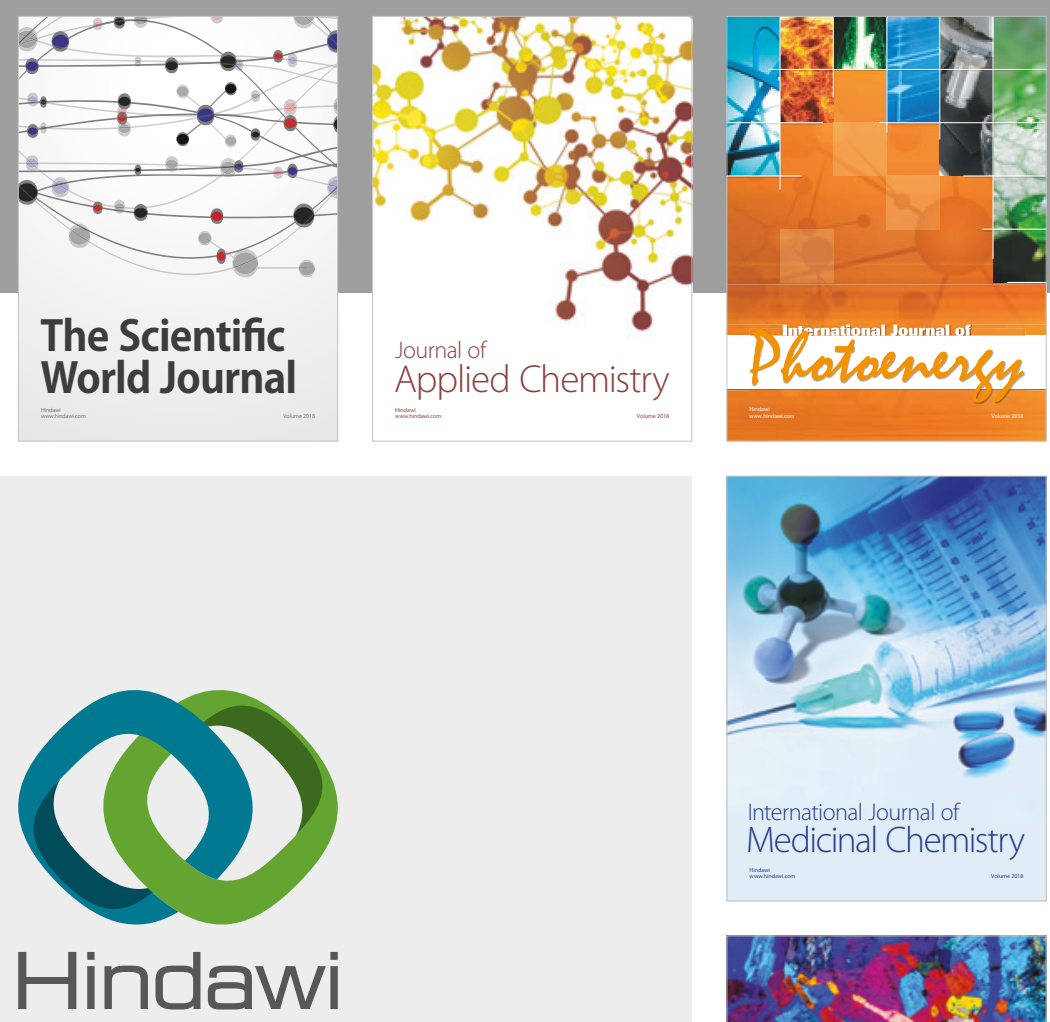

Submit your manuscripts at

www.hindawi.com
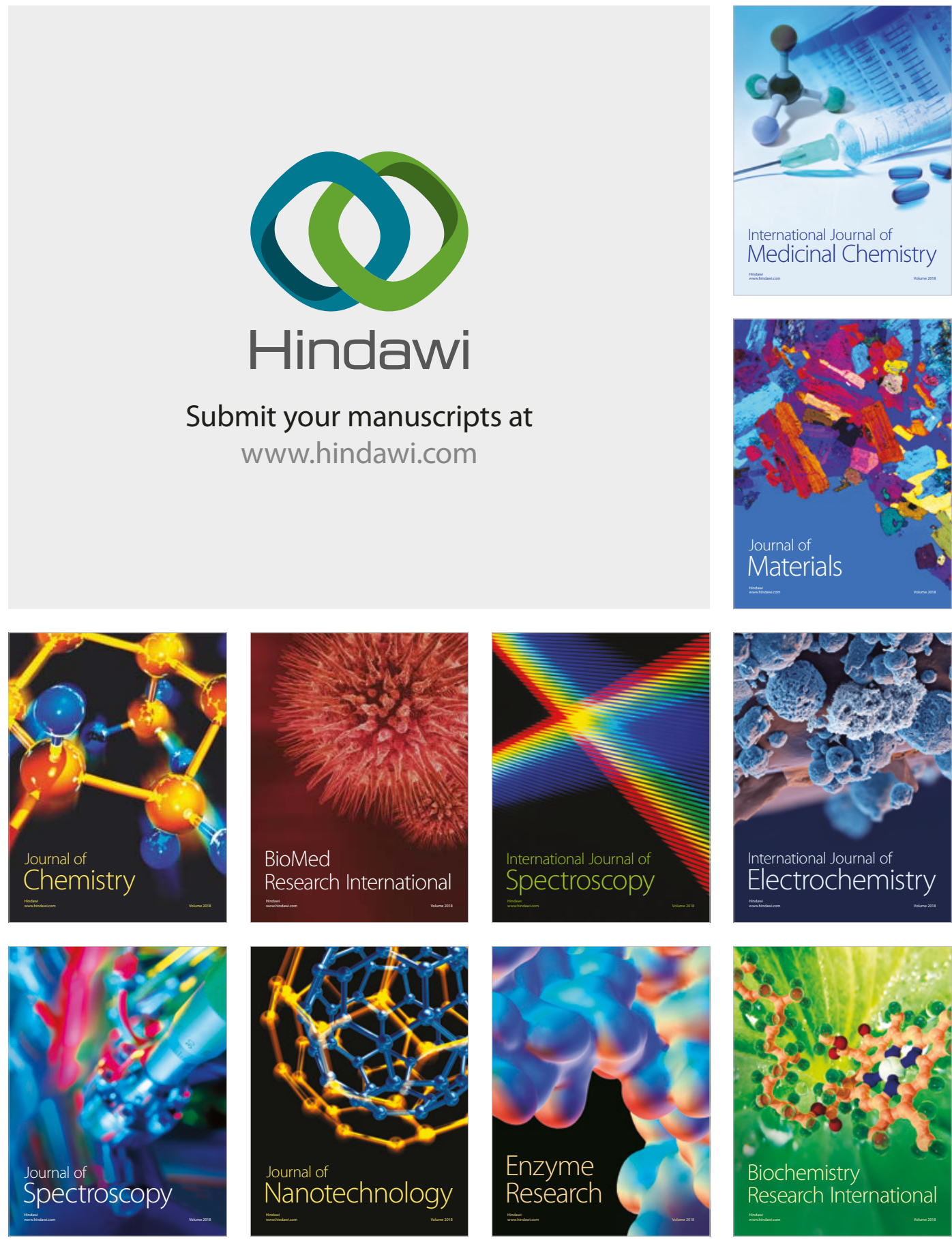
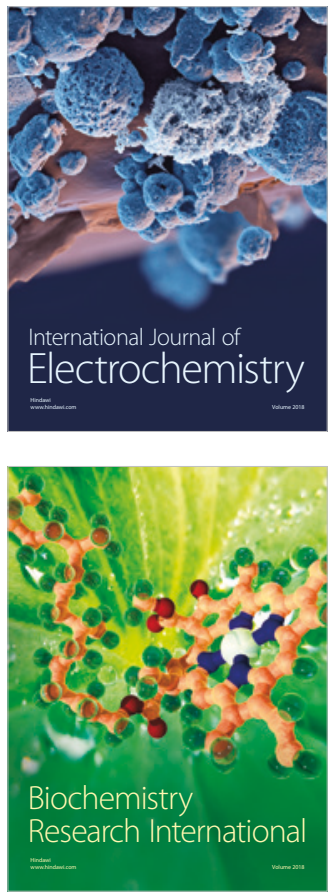